\title{
Active-suspension Design for a Special Road-Rail Vehicle Based on Vehicle-Track Coupled Model Using Genetic Algorithm
}

\author{
Roohollah Talebitooti \\ School of Mechanical Engineering, Iran University of Science and Technology, Tehran, Iran. \\ Reza Bayat \\ School of Automotive Engineering, Iran University of Science and Technology, Tehran, Iran.
}

(Received 8 April 2015; accepted 13 April 2016)

In this paper, a PID controller for a special road-rail vehicle is developed. The dynamic model is derived to properly consider the vehicle and track vibrations. This model contains the effects of track elasticity which makes it more reliable and precious compared to traditional models. The vehicle model contains a two dimensional 10 DOF vehicle model, and the track model consists of 40 sleepers. In addition, the effect of the sleeper number on car-body vibration is investigated. The results show that the present vehicle-track coupled model is more efficient in controller design compared to traditional ones. Finally, tuning of controller gains is performed with the aid of a genetic algorithm, in order to achieve a well-organized active suspension.

\section{NOMENCLATURE}

$\begin{array}{ll}C_{1} & \text { Damping coefficient of primary suspension. } \\ C_{2} & \text { Damping coefficient of secondary suspension. } \\ C F & \text { Cost function in genetic algorithm. } \\ e & \text { Control error. } \\ F & \text { Force matrix of system. } \\ F_{i}, F_{j} & \text { Shear forces exerted on nodes } i \text { and } j . \\ I_{b} & \text { Half-mass moment of inertia of bogie. } \\ I_{c} & \text { Half-mass moment of inertia of car-body. } \\ K_{1} & \text { Stiffness coefficient of primary suspension. } \\ K_{2} & \text { Stiffness coefficient of secondary suspension. } \\ l_{1} & \text { Semi-longitudinal distance between bogies. } \\ l_{2} & \text { Semi-longitudinal distance between } \\ & \text { wheelsets in bogie. } \\ M & \text { Mass matrix. } \\ M_{b} & \text { Half-mass of bogie. } \\ M_{c} & \text { Half-mass of car-body. } \\ M_{i}, M_{j} & \text { Moments about } z \text {-axis exerted } \\ M_{w} & \text { on nodes } i \text { and } j . \\ M O & \text { Half-mass of wheelset. } \\ N & \text { Maximum overshoot of controller. } \\ & \text { Total number of rail-sleeper supporting } \\ N J & \text { points. } \\ q & \text { Number of rail nodes. } \\ u & \text { Time-variant state vector. } \\ V & \text { Actuator force. } \\ Z_{b} & \text { Vehicle forward speed. } \\ Z_{c} & \text { Displacement of bogie. } \\ Z_{r} & \text { Displacement of car-body. } \\ Z_{w} & \text { Displacement of rail. } \\ \theta_{b} & \text { Displacement of wheelset. } \\ \theta_{c} & \text { Pitch angle of bogie. } \\ & \text { Pitch angle of car-body. } \\ & \end{array}$

\section{INTRODUCTION}

Rail transportation is one of the most common forms of transportation in the world. In order to provide a comfortable trip, using active suspension systems in these vehicles has become one of the most effective technologies in the transportation industry.

So far, there exist mainly two theories on railway vehicle dynamics. One is the traditional theory of railway vehicle dynamics, ${ }^{1}$ and the other is the vehicle-track coupled theory. ${ }^{2}$ The traditional theory of railway vehicle dynamics usually focuses on the railway vehicle itself without considerations of the dynamic behavior of the track. In the vehicle-track coupled theory, the track is treated as an elastic structure. Vibrations of the vehicle can be transmitted to the track via the wheel-rail contact and excite vibrations of the elastic track structure, which can in reverse influence the vibrations of the vehicle. Therefore, the vibrations of the vehicle and the track are essentially coupled with each other. ${ }^{2}$

For various research purposes, different types of models have been presented. To study the feasibility for improving ride quality using magnetorheological dampers, a nine DOF model of railway vehicles was developed, including vertical, pitch and roll motions of car-body and trucks. ${ }^{3}$ Also, a 17 DOF model of a semi-active suspension system was used to improve the ride quality on train. ${ }^{4}$ In a study done by Sezer and Atalay, ${ }^{5}$ a 54 DOF model was established to design a fuzzy controller to reduce the vertical, lateral, and angular vibration of a rail vehicle containing a body, three bogies, and six axles. Track models presented in the aforementioned papers were considered rigid.

Investigating safety limits against derailment, several models have been proposed to consider the track vibration. A coupling model of vertical and lateral vehicle-track interaction was proposed by Zhai et al. ${ }^{6}$ in which the vehicle subsystem was demonstrated as a multi-body system with $37 \mathrm{DOF}$, and the track substructure was modeled as a discretely supported system of elastic beam. In addition, the vibration of the train as well as the track was discussed, where the rail was modeled based on the finite element method. ${ }^{7}$ Another similar work was done by Uzzal et al., ${ }^{8}$ in which the dynamic model was presented with the aid of partial differential equations. More- 


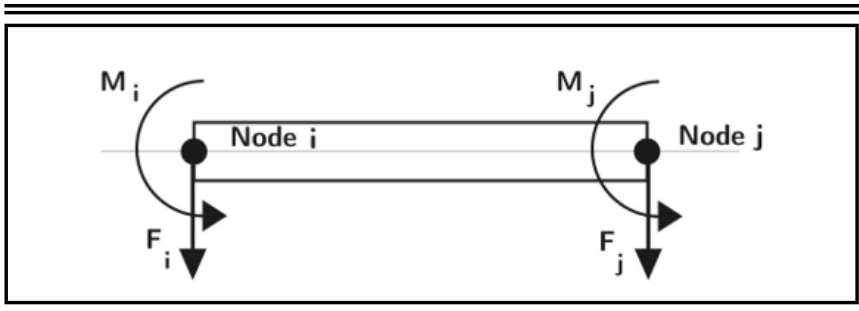

Figure 1. Beam elements for the rail structure.

over, in order to review the vibration of a vehicle and track to a single rail irregularity, Zakeri et al. ${ }^{9}$ presented general equations of a vehicle-track coupled system in a matrix form using finite element method. Furthermore, a road-rail fire-fighting vehicle was considered to demonstrate the effectiveness of the vehicle-track coupled model. ${ }^{11}$

As mentioned in the above literatures, most studies have examined the vibration of railway vehicles, and the track is assumed as a rigid body that may lead to significant errors in the mathematical models; therefore, it is inaccurate. In some of the literatures reviewed above, the vehicle-track coupled model has been used. However, the sheer stress component between the ballast masses is completely ignored. Although both of these assumptions have been considered in a few of the studies, no active suspension is involved there.

In this paper, an active suspension system is applied to a vehicle-track coupled model in order to control the vertical and pitch vibrations of the car-body. This model includes a 10 DOF model for the vehicle and a track, including a rail, a sleeper, and a ballast, as well as consideration of the sheer stress components of the ballast. A new code is developed in MATLAB to study the vibration response of the system. Moreover, an active PID controller is designed to reduce the vibration. Tuning the corresponding parameters of the controller, a genetic algorithm code is established. The results show that using the active controller reduces the acceleration of the carbody by more than $60 \%$. Furthermore, the effects of the vehicle speed on efficiency of the active controller indicate that the controller performance is gradually reduced by increasing the vehicle speed.

\section{MODELLING}

The vehicle system model used in this study consists of a car-body supported by two bogies, each of which has two axels. Without considering the yaw and roll motions of the carbody and bogies, the total DOF of the model is 10: the vertical displacement of the car-body, the pitch angle of the car-body with respect to its center of mass, the vertical displacements of bogies, the pitch angles of bogies with respect to their center of mass, and the vertical displacements of wheel sets. In this paper, vehicle equations proposed by Li et al. ${ }^{10}$ were used which are deduced according to the Newton's laws of motion.

Based on the model presented by Li et al., ${ }^{10}$ it is assumed that the track includes a rail mass, sleepers, and ballast masses. With the aid of finite element method, the rail model is established with applying the Euler-Bernoulli beam element type presented by Liu ${ }^{11}$ (Fig. (1)). Other track equations related to sleepers and ballast masses are utilized from the track equations presented by $\mathrm{Li}$ et al. ${ }^{10}$

The vehicle and track coupled model is shown in Fig. (2). It is proved in Section 3 that the rail is long enough to neglect the boundary effects, so every deflection in both ends of the rail is assumed to be zero. It should be mentioned that the vehicle

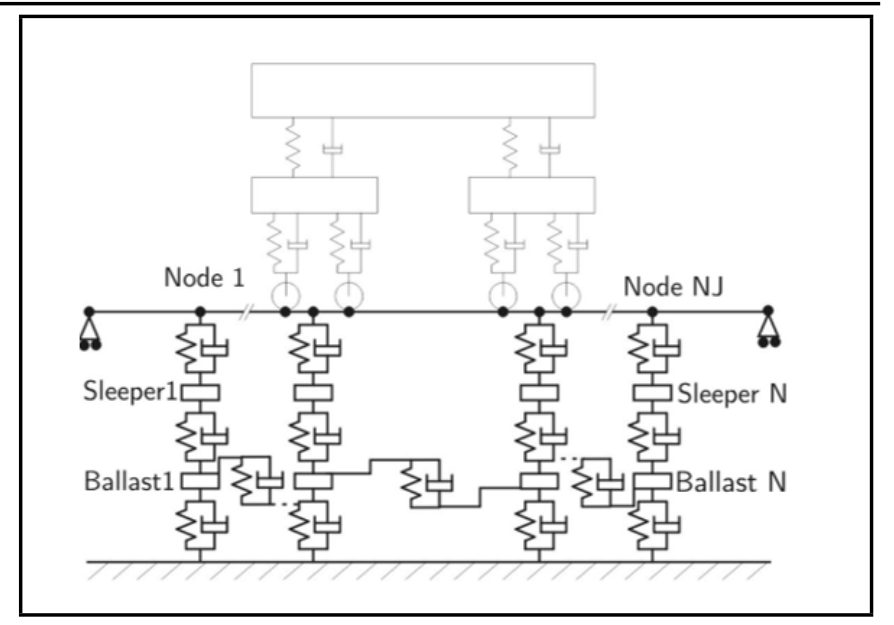

Figure 2. Vehicle-track coupled model.

is placed at the center of the track. Finally, the corresponding vibration equation of the vehicle-track coupled model shown in Fig. (2) can be written in standard form as:

$$
M \ddot{q}+C \dot{q}+K q=F .
$$

The matrices $M, K$, and $C$ are assembled according to (2) as follows:

$$
\left[\begin{array}{cccc}
\text { Carbody } & 0 & 0 & 0 \\
0 & \text { Rail } & R / S & 0 \\
0 & R / S^{T} & \text { Sleeper } & S / B \\
0 & 0 & S / B^{T} & \text { Ballast }
\end{array}\right]
$$

where the sub-matrices $R / S, S / B$ represent the interaction between rails and sleepers, sleepers and ballast respectively. In Fig. (2), it is apparent that dynamic contact force between wheel and rail is assumed as non-linear equation. ${ }^{9}$

\section{NUMERICAL PROCEDURE}

A numerical code is developed in MATLAB to investigate the vibration of vehicle-track interaction. It should be noted that the specifications of the vehicle and track are the same as what is used by Li et al. ${ }^{10}$ Matrices of the mass, stiffness and damping are square, and all have $10+2 N J+2 N$ elements, where $N J$ is the number of rail nodes on which an external force is exerted, and $N$ is the number of sleepers. So, $N J$ is $N$ plus four points that wheels touch rail. Figure (3) shows the effect of these parameters on the vibration of the car-body. Also, it can be depicted that by increasing the number of sleepers and nodes, the acceleration response is getting more improved into real one. It also illustrates that by increasing the number of sleepers and nodes, the dominant period of response increases. Since displacement diagrams for the higher number of sleepers and nodes have less concavity, it can be concluded that increasing the number of sleepers and nodes results in the decrease of the car-body acceleration. Decreasing the car-body acceleration can be expressed by the fact that by adding the length of the rail, the effect of the boundary condition is diminished, and the track is more reasonable in conditions.

Since overloads on the wheel are predicted when the rigid track (traditional model) is considered, further acceleration (concavity of response) on the car-body is observed. In order to take away from the traditional model, the number of sleepers is improved in the presented model. Therefore, the track model becomes softer, and the applied force between wheel and track 


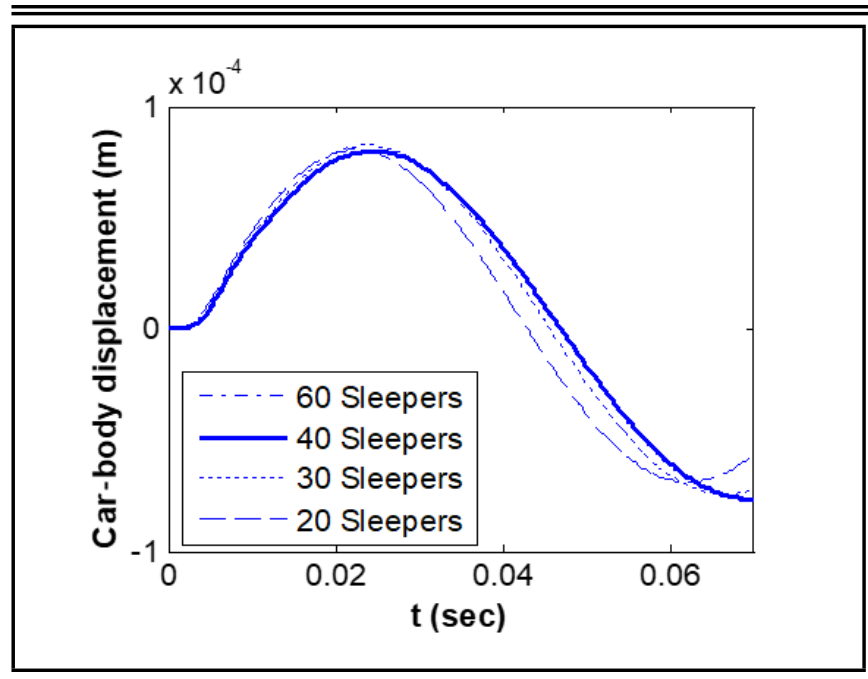

Figure 3. The effect of sleeper number in car-body vibration.

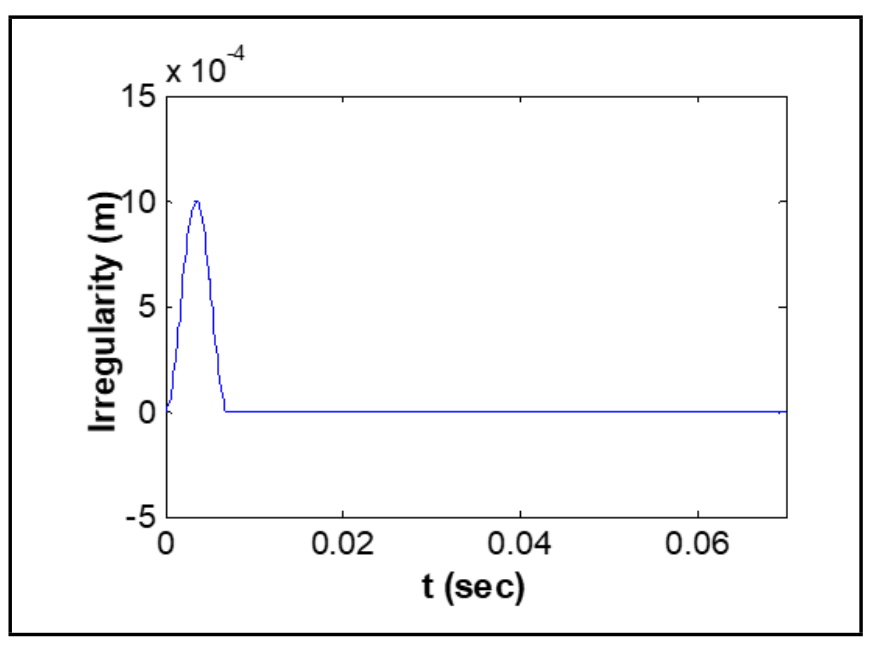

Figure 4. Surface irregularity.

approaches the actual one. In other words, the overestimated acceleration on the car-body is removed by omitting the overloads in the present model. As mentioned above, choosing the values of $N$ and $N J$ as 40 and 44, respectively, leads to a reliable model.

\section{VERIFICATION OF THE MODEL}

The present model is verified here with the aid of two viewpoints. Firstly, the body response of the present model to an irregularity shown in Fig. (6) is obtained assuming a great number for the stiffness of the track. Then, the response is compared with that of the model reported by Li et al. ${ }^{10}$ As depicted in Fig. (7), an excellent agreement is easily observable.

Secondly, the present model is compared with the models presented by Uzzal et al., ${ }^{8}$ and Sun and Dhanasekar. ${ }^{12}$ In the work done by Uzzal et al., ${ }^{8}$ dynamic analysis of a railway vehicle moving on an elastic track is performed. A five DOF model is assumed for the vehicle that contains vertical displacement of the vehicle car-body, bogie's pitch and vertical displacement, and vertical motion in two axles. The track model is similar to the one previously depicted in Fig. (2). Using the vehicle and track characteristics of that model into present model, the results of this comparison are illustrated in Fig. (6).

As shown in this figure, there is a good agreement between these two models. In other words, in both models, the con-

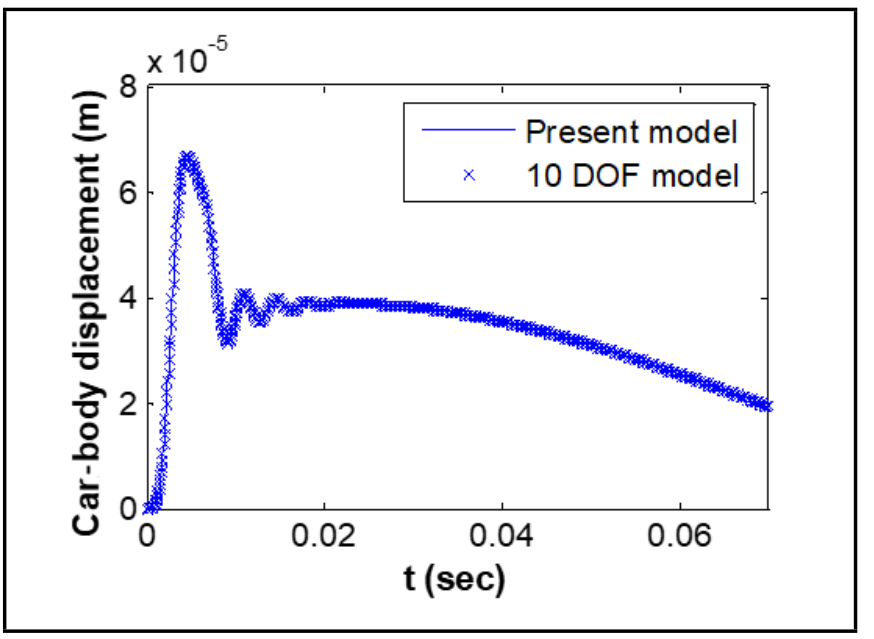

Figure 5. Comparison between theresponse of a 10 DOF model and vehicletrack coupled model with a high stiffness track.

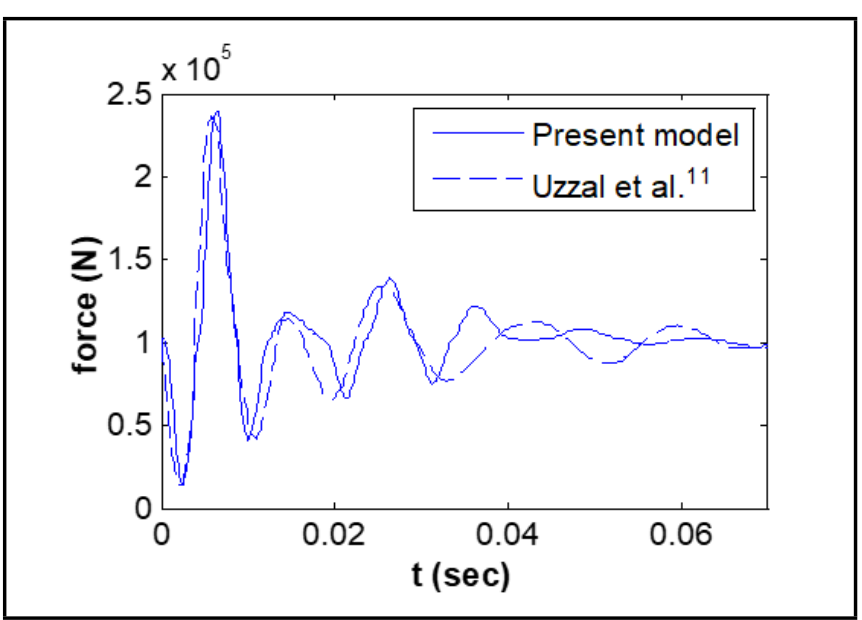

Figure 6. Wheel-rail contact force of current model and the model presented by Uzzal et al. ${ }^{8}$

tact force between the wheel and track falls, due to onset of contacting the wheel flat irregularity with the track. Then, the contact force increases because the wheel suddenly impacts the track. The dominant period of oscillation of the contact force is approximately 10 milliseconds. However, a slight difference between two models was observed 30 milliseconds later, due to the differences between finite element method and partial differential solution. This difference influences computation of the damping matrix. In other words, it slightly affects the wheel-track damping force. Nevertheless, this has a negligible effect on car-body vibration.

Another comparison has been done using the 10 DOF vehicle model used by Sun and Dhanasekar, ${ }^{12}$ as well as the experimental work performed by Newton and Clark. ${ }^{13}$ In the work done by Sun and Dhanasekar, ${ }^{12}$ a track model with four-layer is considered, and the Hertz contact coefficient is deduced from Johnson. ${ }^{15}$ However, in present work, the recent model of contact phenomenon presented by $\mathrm{Zhai}^{2}$ is developed. It can be observed from Fig. (7) that when the wheel flat irregularity touches the track, the contact force reduces to zero. This means the wheel and the rail separate for a while. When they meet again, an enormous peak force is induced between them. This phenomenon is reasonably predicted in these three methods. Both numerical models show some disagreements with the experimental data. This is due to the discrepancy that occurred as a result of disagreement between the real and calculated damp- 


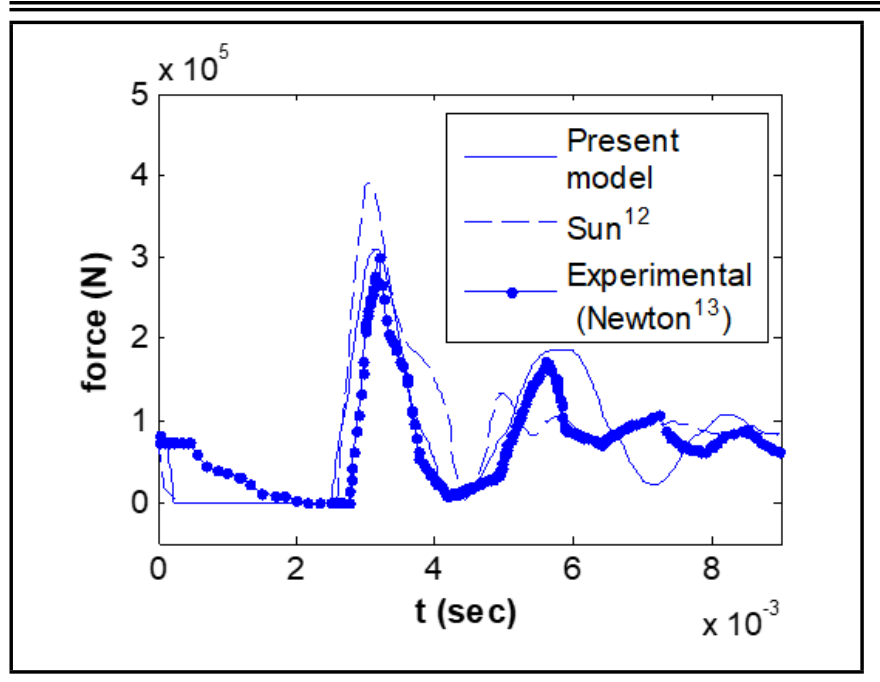

Figure 7. Wheel-rail contact force of current model and the model presented by Sun and Dhanasekar, ${ }^{12}$ and Newton and Clark. ${ }^{13}$

ing values of track components. In addition, the results of Sun and Dhanasekar ${ }^{12}$ give the maximum force much higher than that of the experimental model, ${ }^{13}$ whereas the present work gives the maximum force much more reliable.

These two comparisons confirm the reliability of the present model in simulating the vehicle- track coupled dynamics, especially for designing the controller, in which the reduction of maximum contact force is of high importance.

\section{COMPARING VEHICLE-TRACK COUPLED MODEL WITH 10 DOF MODEL REGARD- ING VEHICLE BODY RESPONSE}

This section discusses the importance of modelling accuracy in controller designing. At first, in order to illustrate the importance of considering track vibrations, car-body response of the 10 DOF model (traditional model) was compared to the response of the vehicle-track coupled model (present model). Then, in the next section, suitable PID controller gains are calculated based on the vehicle-track coupled model using the genetic algorithm.

Applying the irregularity shown in the Fig. (4) to the models, vertical displacement of the car- body for the traditional and the present model was obtained, as illustrated in Fig. (8). Significant differences are observed comparing the results of these two models. This is due to the fact that in the traditional model, the stiffness of the track is not considered. In present work, as the elasticity of the track is fully considered, it can be imagined that the vehicle travels on a softer bed. Apparently, applying spring elements to a vibration system in seriesform causes decreasing stiffness; consequently, oscillations decrease, and thus displacements increase. Moreover, the amplitude of the acceleration of car-body (concavity of displacement graph) decreases. In other words, it can be seen that present model differs from the 10 DOF model in a significant quantity; therefore, the results of the present model is of a higher accuracy to design PID controller for the road-rail vehicle.

\section{ACTIVE SUSPENSION SYSTEM}

\subsection{Active Suspension System Modeling}

Using active secondary suspension is an efficient way to reduce car-body vibrations. ${ }^{14}$ Secondary active suspension im-

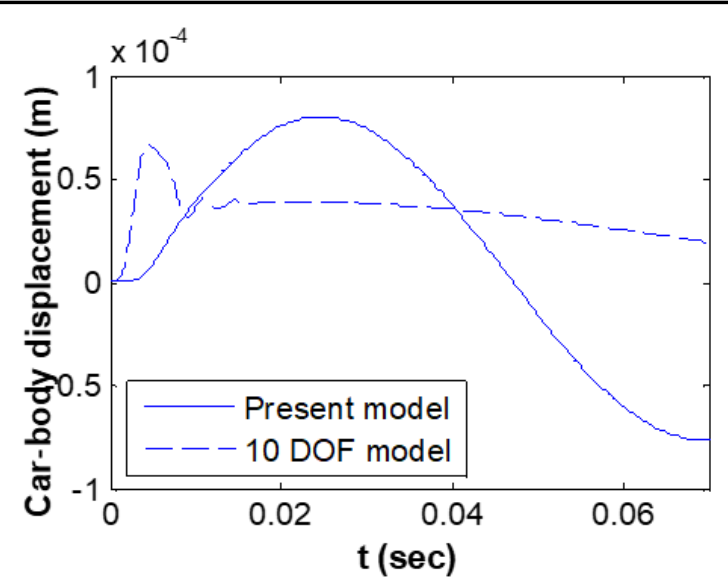

Figure 8. Comparison between the car-body responses of a 10 DOF model and vehicle-track coupled model.

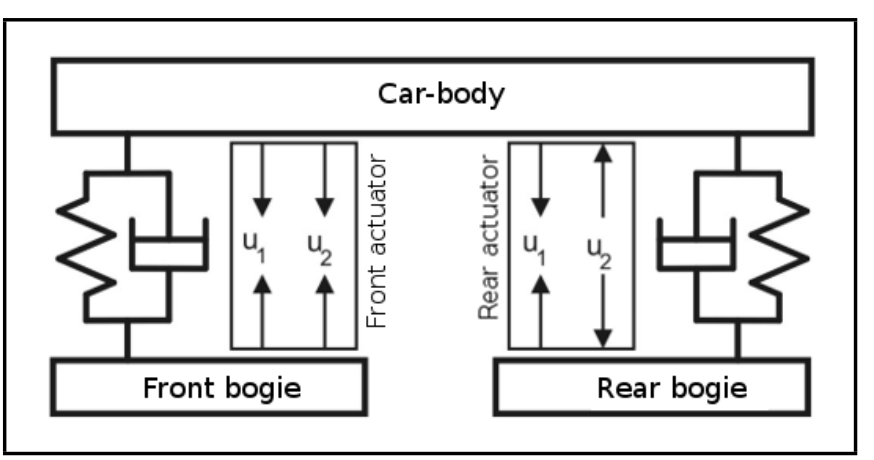

Figure 9. Schematic of present secondary active suspension system.

proves the car-body dynamic response and provides a better isolation to the track irregularities compared to using only passive springs and dampers. Actuators can be replaced with the passive suspensions, and the suspension behavior will be completely controlled via active means. In practice, however, it is more beneficial to use actuators in conjunction with passive components. ${ }^{15}$

Figure (9) shows a schematic of active components. In order to ease mathematic equations, the front and rear actuators * forces were broken into two components $u_{1}$ as vertical force and $u_{2}$ as pitch moment.

In this model, the actuator forces are expressed as:

$$
\begin{aligned}
& u_{1}+u_{2}=u_{f} ; \\
& u_{1}-u_{2}=u_{r} ;
\end{aligned}
$$

where $u_{r}$ and $u_{f}$ are the rear and front actuators ' forces.

Because of using actuators in the suspension system, the vertical force and moment exerted on the car-body and bogies should be revised. Equations (5) and (6) are the revised form of the car-body and bogies equation proposed by Li et al. ${ }^{10}$ with consideration of the actuators' forces. Equations of vertical displacement and pitch motion of car-body are as follows:

$$
\begin{aligned}
& M_{c} \ddot{Z}_{c}+2 C_{2} \dot{Z}_{c}- 2 K_{2} Z_{c}-C_{2} \dot{Z}_{b 1}-K_{2} Z_{b 1} \\
&-C_{2} \dot{Z}_{b 2}-K_{2} Z_{b 2}=2 u_{1}
\end{aligned}
$$

$$
\begin{aligned}
I_{c} \ddot{\theta}_{c}-2 C_{2} l_{1}^{2} \dot{\theta}_{c}+ & 2 K_{2} l_{1}^{2} \theta_{c}-C_{2} l_{1} \dot{Z}_{b 1}-K_{2} l_{1}^{2} Z_{b 1} \\
& +C_{2} l_{1} \dot{Z}_{b 2}+K_{2} l_{1} Z_{b 2}=2 u_{2} l_{1}
\end{aligned}
$$


where $M c$ is the half-mass of the car-body, $I_{c}$ is the halfmass moment of inertia of the car-body, $K$ and $C$ represent the stiffness coefficient and damping coefficient of suspension elements, and the subscripts 1 and 2 are used to identify primary and secondary suspension elements.

Respectively, the vertical displacement of the front and rear bogies are written as:

$$
\begin{array}{r}
M_{b 1} \ddot{Z}_{b 1}+C_{2}+2 C_{1} \dot{Z}_{b 1}+K_{2}+2 k_{1} Z_{b 1}-C_{2} \dot{Z}_{c} \\
+l_{1} \dot{\theta}_{c}-K_{2} Z_{c}+l_{1} \theta_{c}-C_{1} \dot{Z}_{w 1}-K_{1} Z_{w 1}-C_{1} \dot{Z}_{w 2} \\
-K_{1} Z_{w 2}=-u_{1}-u_{2}
\end{array}
$$

$$
\begin{array}{r}
M_{b 2} \ddot{Z}_{b 2}+C_{2}+2 C_{1} \dot{Z}_{b 2}+K_{2}+2 k_{1} Z_{b 2}-C_{2} \dot{Z}_{c} \\
-l_{1} \dot{\theta}_{c}-K_{2} Z_{c}-l_{1} \theta_{c}-C_{1} \dot{Z}_{w 3}-K_{1} Z_{w 3}-C_{1} \dot{Z}_{w 4} \\
-K_{1} Z_{w 4}=-u_{1}+u_{2} ;
\end{array}
$$

where $M_{b 1}$ and ${ }_{b 2}$ are the half-mass of the bogies, $I_{b 1}$ and $I_{b 2}$ are the half-mass moment of inertia of the bogies, $l_{1}$ and $l_{2}$ represent, respectively, the semi-longitudinal distance between bogies and the semi-longitudinal distance between wheelsets in bogies.

Considering the above relationships, the governing equations of the system can be written in a matrix form as:

$$
M \ddot{q}+C \dot{q}+K 1=F+u
$$

where $u$ is the actuator force. For the PID controller $u$ is followed as:

$$
u(t)=K_{p} e(t)+K_{I} \int_{0}^{t} e(t) d t+K_{D} \frac{d}{d t} e(t)
$$

where $K_{p}, K_{i}$, and $K_{d}$ are, respectively, proportional, integral, and derivative gains of the PID controller. The variable $e(t)$ is the control error.

\subsection{Obtaining the Gains of the PID Controller and Evaluating Results}

First, in order to find out the gains of the controller, the irregularity shown in Fig. (4) is applied to the system, and vibration of the car-body is measured. Then, the controller gains are optimized by using the genetic algorithm to minimize the car-body vibrations. The objective function of the genetic algorithm is to reduce integral of absolute error and maximum overshoot, written as:

$$
C F=M O+\int e(t) d t
$$

where $C F$ is cost function and $M O$ is maximum overshoot.

Parameter specifications for the genetic algorithm are listed in Table 1. One of those specifications is a crossover fraction. A crossover fraction is the fraction of individuals in the next generation, other than elite children, that are created by

\begin{tabular}{|c|c|c|}
\hline Parameter & \multicolumn{2}{|c|}{ Characteristic value } \\
\hline Number of variables & \multicolumn{2}{|c|}{3} \\
\hline Population Size & \multicolumn{2}{|c|}{20} \\
\hline \multirow[t]{2}{*}{ Crossover fraction } & For u1 & For u2 \\
\hline & 0.8 & 0.4 \\
\hline Generations & \multicolumn{2}{|c|}{100} \\
\hline Stall generation & \multicolumn{2}{|c|}{100} \\
\hline Function tolerance & \multicolumn{2}{|c|}{$1 \mathrm{e}-10$} \\
\hline Constraints tolerance & \multicolumn{2}{|c|}{$1 \mathrm{e}-10$} \\
\hline Select function & \multicolumn{2}{|c|}{ Roulette } \\
\hline Crossover function & \multicolumn{2}{|c|}{ Scattered } \\
\hline
\end{tabular}
crossover (that is, mating). The rest are generated by mutation. A crossover fraction of one means that all children other than elite individuals are crossover children. A crossover fraction of zero means that all children are mutation children. Choosing the best crossover fraction leads to better optimization, so the effect of the crossover fraction was investigated for both actuators that can be seen in Fig. (10). Figure (11) shows how fitness
Table 1. Genetic algorithm specifications.

Table 2. Optimized controller gains.

\begin{tabular}{|c|c|c|c|}
\hline & $K_{p}$ & $K_{I}$ & $K_{D}$ \\
\hline$u_{1}$ & 3535659 & 68314788 & 32983 \\
\hline$u_{2}$ & 13313522 & 14352104 & 258263 \\
\hline
\end{tabular}

values are converged by assuming the best crossover fraction for minimizing cost function. Furthermore, 100 was selected as the number of generations because increasing this parameter does not result in a noticeable change in fitness values in either optimizations for vertical or angular actuators. Optimized controller gains are listed in Table 2 .

The responses of car-body acceleration in both active and passive suspension systems are compared in Fig. (12). The effect of applying the active suspension system on the acceleration of the car-body is clearly observable from these figures. The reduction percentage of maximum vertical and pitch accelerations of the car-body are respectively $58 \%$ and $73 \%$. In addition, by assuming $\pm 0.02 \mathrm{~m} / \mathrm{s}^{2}$ as marginal acceleration for vertical acceleration and $\pm 0.002 \mathrm{rad} / \mathrm{s}^{2}$ for pitch acceleration, the settling time for those accelerations are $0.053 \mathrm{~s}$ and $0.051 \mathrm{~s}$ while for the passive suspension system, those were $1.3 \mathrm{~s}$ and 2.9 s. Therefore, the new presented active control can effectively enhance the ride quality of the vehicle.

In Fig. (13), the effect of vehicle speed is investigated for speeds $1.2 \mathrm{~V}$ and $0.8 \mathrm{~V}$ as well, where $V$ is the previous speed amounting to $27 \mathrm{~km} / \mathrm{h}$. As illustrated, by increasing the vehicle speed, the maximum car-body acceleration increases, and the dominant period decreases. By increasing vehicle speed, the acceleration of irregularity increases and its period decreases, so the acceleration of car-body rises, and the dominant period of car-body acceleration lowers. In Fig. (14), the forces of actuators for different vehicle speeds are depicted. These figures justify this phenomenon. The higher the speed, the worse the actuator can reflect. As a result, maximum acceleration increases.

The percentage of maximum acceleration reduction of the car-body is given in Table 3. As listed, by increasing the vehicle speed, the efficiency of active suspension is reduced. The loss of efficiency is due to increasing frequency and input force that increases control error, so it reduces the efficiency of active suspension. In other words, the designed controller performs better at low speeds.

Based on the above discussion, the designed PID controller for the suspension of the road-rail fire-fighting vehicle reduces car-body vibration very well and improves the ride quality.

Table 3. Maximum acceleration reduction (\%).

\begin{tabular}{|c|c|c|}
\hline Pitch Acc. & Vertical Acc. & Velocity \\
\hline $0.8 \mathrm{~V}$ & $65 \%$ & $78 \%$ \\
$\mathrm{~V}$ & $58 \%$ & $73 \%$ \\
$1.2 \mathrm{~V}$ & $53 \%$ & $71 \%$ \\
\hline
\end{tabular}




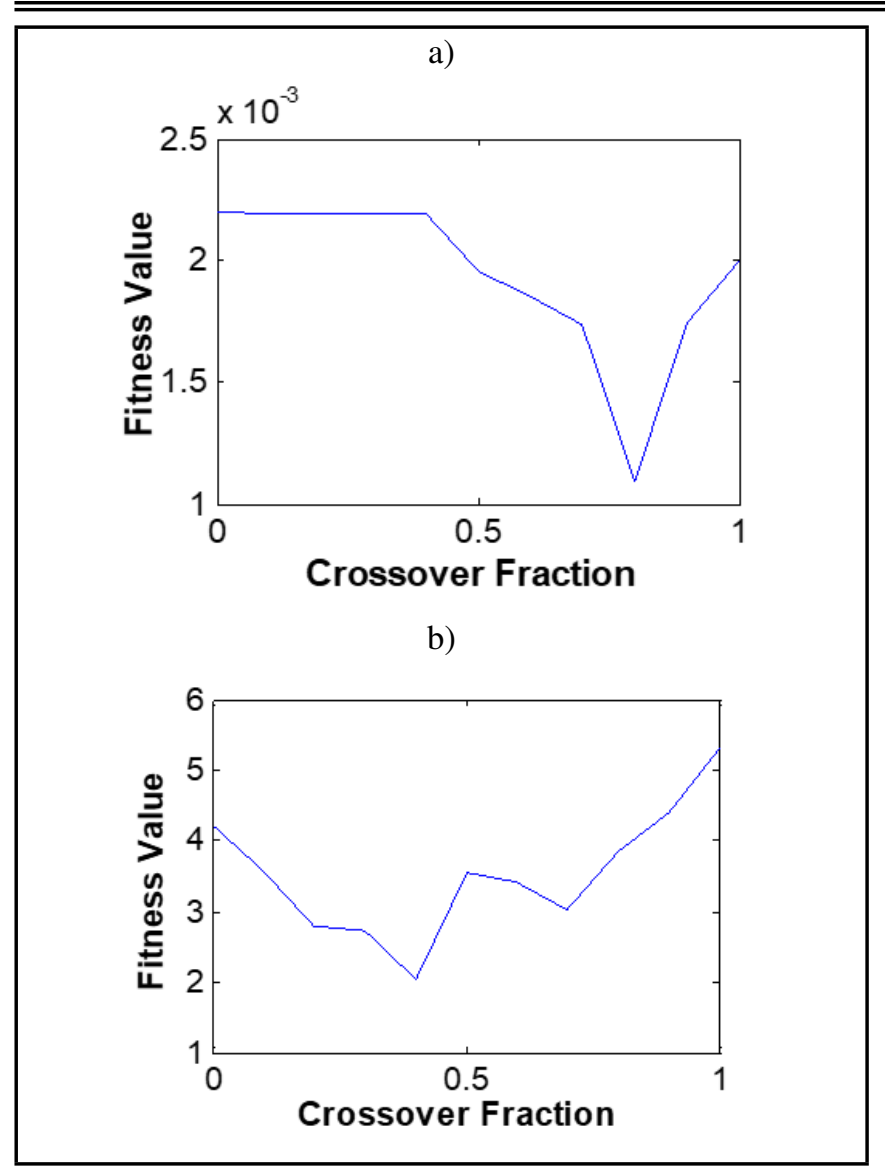

Figure 10. The effect of crossover fraction on best fitness value for: (a) actuator No.1 ands (b) actuator No.2.

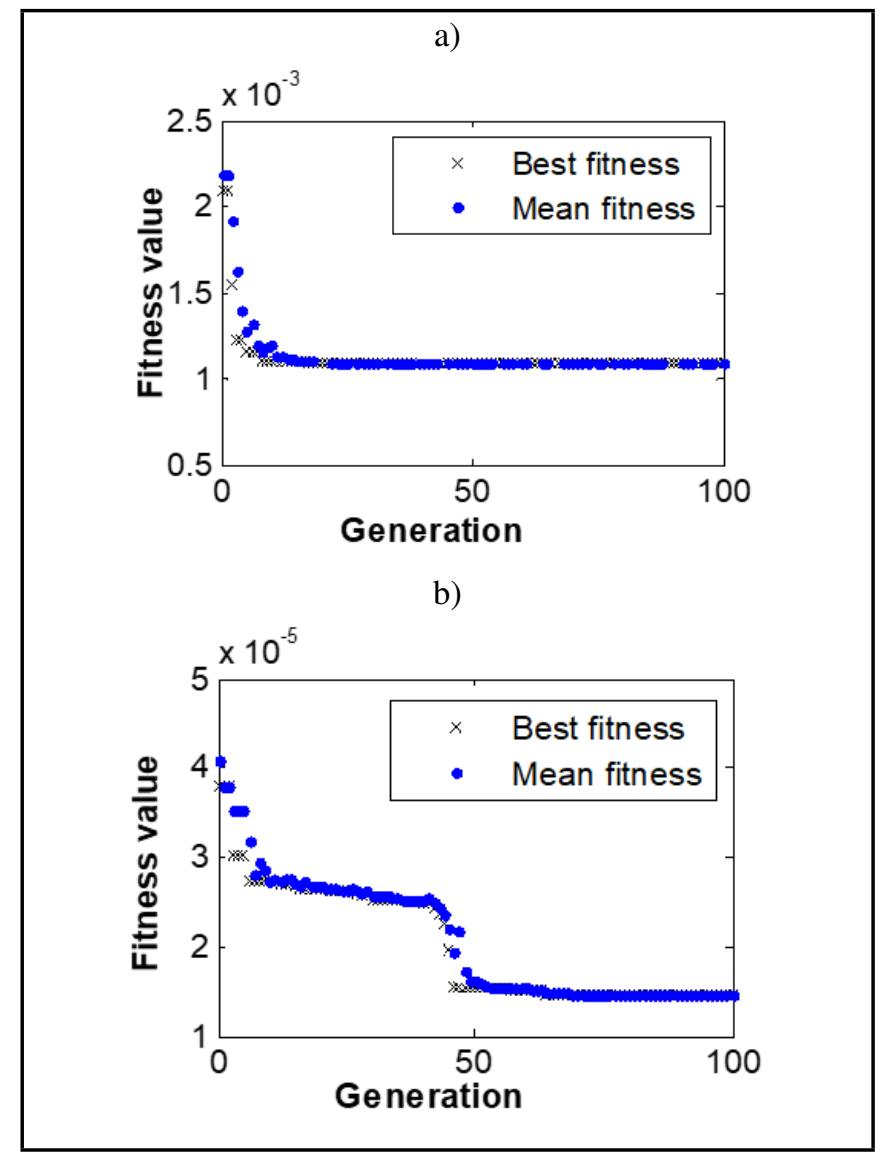

Figure 11. Convergence of fitness value for: (a) actuator No. 1 and (b) actuator No. 2. a)

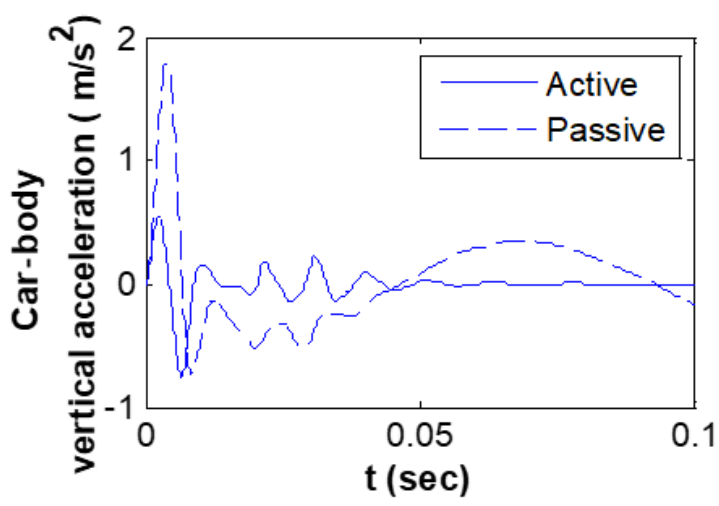

b)

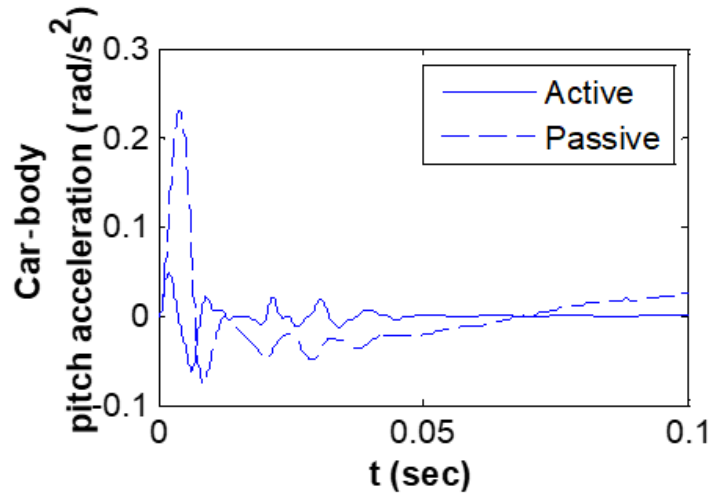

Figure 12. Car-body vertical and pitch acceleration.

a)

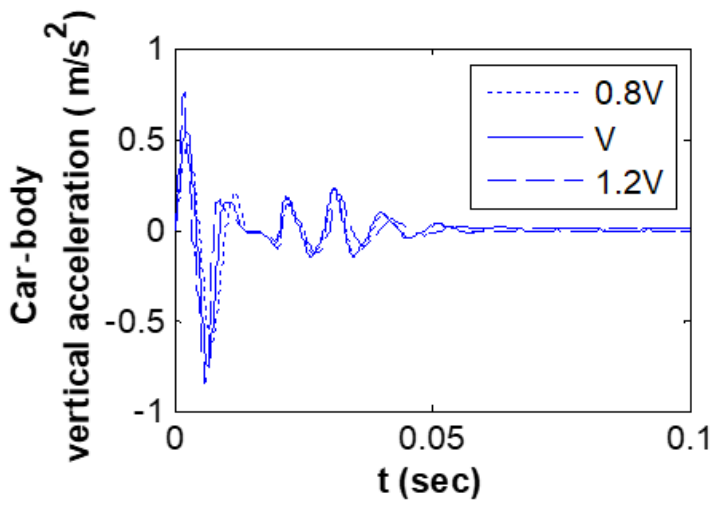

b)

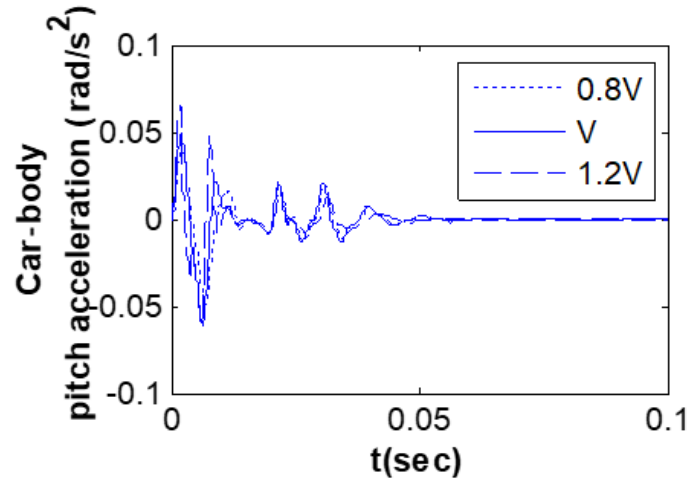

Figure 13. Car-body vertical and pitch acceleration for different speeds. 


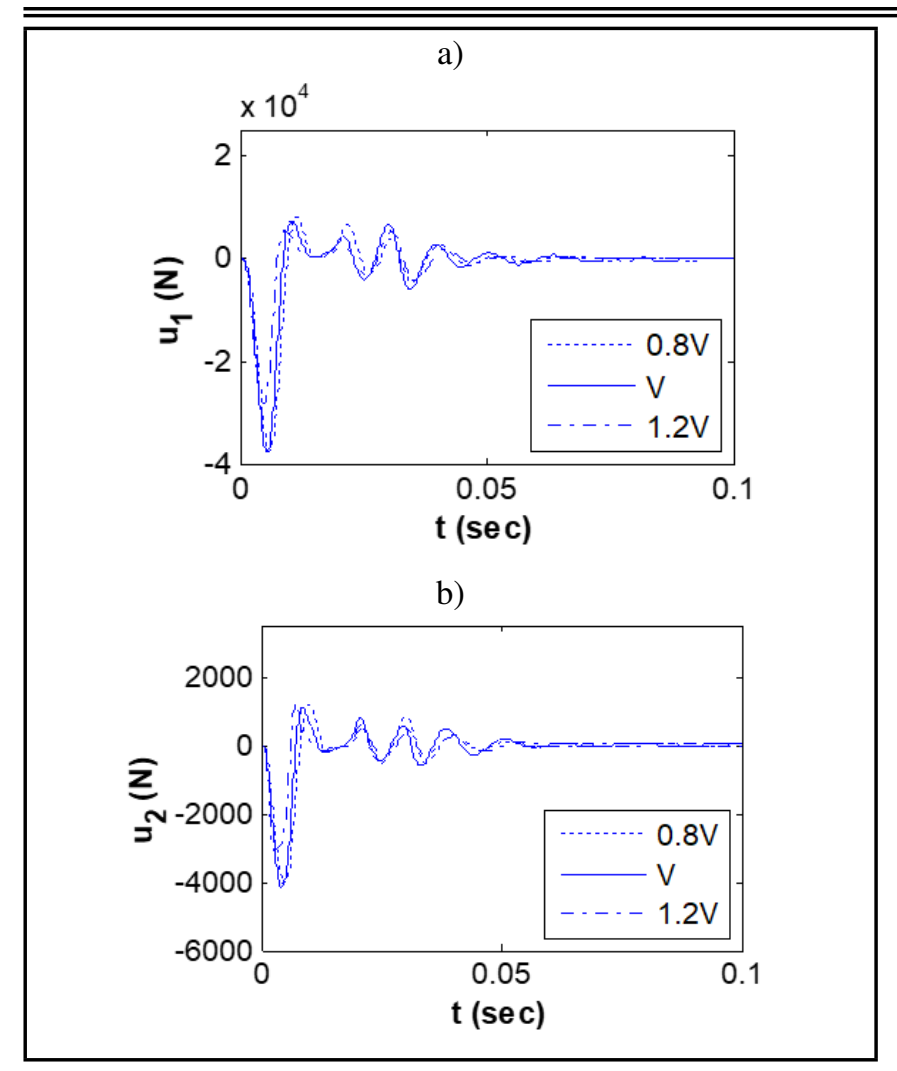

Figure 14. The force of actuators at different speeds.

\section{CONCLUSIONS}

In this paper, with the aid of a 10 DOF vehicle model, a vehicle-track coupled model is derived. The governing equations of the system are modeled in Simulink, and thus carbody accelerations are obtained. The results indicate that the vehicle-track coupled model can affect the system's responses and then controller design. Therefore, a PID controller is designed based on the vehicle-track coupled model to improve the ride quality of the road-rail fire-fighting vehicle.

In particular, the results can be summarized as follow:

1. Considering vehicle-track coupled model has a noticeable effect on the the system response.

2. By increasing the number of sleepers and rail length, the car-body displacement increases, and the amplitude of its acceleration decreases.

3. Supposing a track consisting of 40 sleepers is appropriate when considering car-body vibrations.

4. Using the finite element method shows an acceptable result for simulating the vehicle-track coupled model.

5. Using an active suspension system has a significant effect on reducing car-body vibration amounting to more than $60 \%$; consequently, it improves ride quality of road-rail vehicles. This effect declines by increasing velocity.

\section{REFERENCES}

1 Garg, V. K. and Dukkipati, R. V. Dynamics of railway vehicle systems, Academic Press Canada, Toronto, (1984), 1st Edition.

2 Zhai, W. M. Vehicle-track coupling dynamics, Science Press Pub., China, (2007), 3rd Edition.
3 Liao, W. H. and Wang, D. H. Semi-active vibration control of train suspension systems via magnetorheological dampers, Journal of Intelligent Material Systems and Structures, 14 (3), 161-172, (2003). https://dx.doi.org/10.1177/1045389X03014003004

4 Wang, D. H. and Liao, W. H. Semi-active suspension systems for railway vehicles using magnetorheological dampers. Part I: system integration and modeling, Vehicle System Dynamics, 47 (11), 1305-1325, (2009). https://dx.doi.org/10.1080/00423110802538328

5 Sezer, S. and Atalay, A. E. Dynamic modeling and fuzzy logic control of vibrations of a railway vehicle for different track irregularities, Simulation Modeling Practice and Theory, 19 (9), 1873-1894, (2011). https://dx.doi.org/10.1016/j.simpat.2011.04.009

6 Zhai, W. M., Cai, C. B., and Guo, S. Z. Coupling model of vertical and lateral vehicle-track interaction, Vehicle System Dynamics, 26 (1), 61-79, (1996). https://dx.doi.org/10.1080/00423119608969302

7 Lei, X. and Noda, N. -A. Analyses of dynamic response of vehicle and track coupling system with random irregularity of track vertical profile. Journal of Sound and Vibration, 258 (1), 147-165, (2002). https://dx.doi.org/10.1006/jsvi.2002.5107

8 Uzzal, R. U. A., Ahmed, W., and Rakheja, S. Dynamic analysis of railway vehicle-track interactions due to wheel flat with a pitch-plane vehicle, Journal of Mechanical Engineering, 39 (2), 86-94, (2008). https://dx.doi.org/10.3329/jme.v39i2.1851

9 Zakeri, J. A., Xia, H., and Fan, J.J. Dynamic responses of train-track system to single rail irregularity, Latin American Journal of Solids and Structures, 6 (2), 89-104,(2009).

10 Li, X. W., Zhang, J. W., Lu, T. L., and Xue, L. Optimization of suspension parameters based on vehicle-track coupled model for a special railway vehicle, Journal of Shanghai Jiaotong University, 46 (3), 346-351, (2012).

11 Liu, Y. Lecture notes: Introduction to Finite Element Method, University of Cincinnati, Cincinnati, (2003), 1st Edition.

12 Sun, Y. Q. and Dhanasekar, M. A dynamic model for the vertical interaction of the rail track and wagon system, International Journal of Solids and Structures, 39 (5), 1337-1359,(2002). https://dx.doi.org/10.1016/S00207683(01)00224-4

13 Newton, S. G. and Clark, R. A. An investigation into the dynamic effects on the track of wheel flats on railway wagon, Journal of Mechanical Engineering Science, 21 (4), 87-297, (1979). https://dx.doi.org/10.1243/JMES_JOUR_1979_021_046_02

14 Ornavas, A. On active secondary suspension in rail vehicles to improve ride comfort, Doctoral Thesis in Railway Technology, KTH Engineering Science, Department of Aeronautical and Vehicle Engineering, Stockholm, (2011).

15 Goodall, R. M. and Mei, T. X. Handbook of Railway Vehicle Dynamics, CRS Press, Taylor \& Francis Group, Florida, (2006), 1st Edition.

16 Johnson, K. L. Contact Mechanics, Cambridge University Press, Cambridge, MA, (1985). 